\title{
A PROTEÇÃO JURÍDICA DO CONSUMIDOR NO COMÉRCIO \\ ELETRÔNICO
}

THE LEGAL PROTECTION OF THE CONSUMER IN ELECTRONIC COMMERCE

Kelly Caroline de Carvalho ${ }^{1}$ Renata Romani Castro ${ }^{2}$

ISSUE DOI: 10.21207/1983.4225.455

\section{RESUMO}

Este trabalho aborda aspectos relativos às relações de consumo realizadas por meio da rede mundial de computadores, a internet, sendo ressaltada a aplicação do CDC nos contratos de consumo de eletrônicos. Para justificar a aplicação do Código a estes contratos foram apreciados os aspectos relevantes e a validade jurídica dos mesmos, e ainda destacados os meios e a importância da proteção jurídica dos consumidores nesta modalidade de contratação. Um dos grandes problemas desta forma de contratação é a exposição dos consumidores a situações que evidenciam sua condição de vulnerabilidade frente aos fornecedores. Para que tal obstáculo seja superado, foi realizada a análise da Constituição Federal sobre tema, em seguida, fo-

\footnotetext{
${ }^{1}$ Graduada pela Faculdade de Direito de Franca (2016).

${ }^{2}$ Graduada em Direito pela Faculdade de Direito de Franca (2003). Mestrado em Direitos Coletivos e Cidadania pela Universidade de Ribeirão Preto (2010). Doutoranda pela Faculdade Autônoma de Direito. Atualmente é professor titular da Faculdade de Ituverava Dr. Francisco Maeda e professora colaborada da Faculdade de Direito de Franca. Tem experiência na área de Direito, com ênfase em Direito Processual Civil e Direitos Coletivos.
} 
ram abordados diversos dispositivos do CDC, bem como de outras disposições legais ligadas ao tema, como o Marco Civil da Internet (Lei $\mathrm{n}^{\circ}$ $12.965 / 14$ ) e o Decreto $\mathrm{n}^{\circ} 7.962 / 13$ aplicando-se delas o que melhor se adequa à promoção da defesa desta categoria de consumidores.

Palavras-chave: Relação de Consumo. Comércio Eletrônico. Internet. Direito do Consumidor.

\section{ABSTRACT}

This article discusses aspects related to consumer relations conducted through the Internet, emphasizing the application of the CDC in electronic consumer contracts. In order to justify the application of the Code to these contracts, the relevant aspects and legal validity of these contracts were evaluated, as well as the means and importance of the legal protection of consumers in this modality of contracting. One of the main problems with this form of hiring is the exposure of consumers to situations that show their vulnerability to suppliers. In order to overcome this obstacle, the Federal Constitution was analyzed on the subject, followed by various provisions of the CDC, as well as other legal provisions related to the subject, such as the Civil Internet Framework (Law 12.965/14) and Decree No. $7.962 / 13$, applying the most suitable for the promotion of the defense of this category of consumers.

Keywords: Consumer Ratio. E-commerce. Internet. Consumer Law.

\section{INTRODUÇÃO}

A globalização atrelada à digitalização foram dois dos principais mecanismos que impulsionaram consideravelmente a difusão da informação sobre a sociedade contemporânea.

Uma das rotas de acesso para essa integração foi o desenvolvimento dos meios de comunicação, em especial, a internet. A partir de sua expansão, as pessoas passaram a "digitalizar" cada vez mais o seu dia-adia com mudanças que visam melhorar e facilitar as suas vidas.

Uma das áreas que sofreu impacto deste novo modelo de sociedade foi a do comércio. 
Por conta do crescimento das relações consumeristas, o legislador percebeu que era necessário promover adaptações à legislação brasileira para que fosse possível regulamentar esta crescente modalidade de contratação, pois identificou que além de as relações consumeristas terem passado a fazer parte do dia-a-dia da população, percebeu que o consumidor, o adquirente, na maioria das vezes, estava exposto às práticas abusivas dos fornecedores.

A partir da digitalização das relações comerciais, especificamente das relações de consumo, ficou ainda mais evidente a fragilidade do consumidor face ao fornecedor, pois embora esta nova modalidade de contratação facilitasse a aquisição de produtos ou serviços por meio de alguns cliques pelo computador, também submetia o consumidor a situação extrema de vulnerabilidade, já que nestas contratações acabava se submetendo totalmente à vontade do fornecedor.

Frente à influência que esta modalidade de contratação exerce sobre o mundo jurídico, por conta de seu caráter abrangente, não há momento mais oportuno que este para se abordar esta temática que está em constante aperfeiçoamento e, é tão difundida na sociedade.

Para a confecção deste trabalho foi utilizado o método dedutivo, sendo realizadas pesquisas qualitativas por meio de pesquisas bibliográficas realizadas em doutrinas, páginas de web sites dos tribunais brasileiros e por fim, em web sites relacionados à temática.

\section{A RELAÇÃO JURÍDICA DE CONSUMO}

\subsection{A PROTEÇÃO CONSTITUCIONAL DO CONSUMIDOR}

Até a promulgação da Constituição de 1988, não havia no ordenamento jurídico brasileiro normas de direito material voltadas diretamente para a proteção do consumidor em conflitos de interesses oriundos das relações de consumo. Em vista disso, era aplicada a defesa do consumidor, na medida do possível, legislações esparsas e, quanto à legislação comum, normas de direito comercial, civil e penal.

Com a promulgação da Constituição de 1988, em seu texto ao cuidar dos Direitos e Garantias Fundamentais, estabeleceu no inciso 
XXXII do artigo $5^{\circ}$ que "o Estado promoverá na forma da lei, a defesa do consumidor". 3

A Constituição deixou claro que não seria tarefa apenas da União promover a defesa do consumidor, em razão disso, estipula em seu artigo 24, V e VII que não só a União como também os Estados e o Distrito Federal podem legislar sobre a matéria consumerista.

Além disso, entendeu o Estado que não era o bastante a proteção do consumidor pelos entes estatais, dessa forma, por meio do artigo 170, V da Constituição impõe tal dever também aos empreendedores, empresários ou a qualquer pessoa que pretenda explorar o mercado de consumo, pois só poderão exercer tal direito se observarem as normas de defesa do consumidor.

Apesar de todas estas disposições, a Constituição entendeu que não seria suficiente para promover a defesa do consumidor e, por isso, no Ato das Disposições Constitucionais Transitórias em seu artigo 48 determinou que, após a promulgação da Constituição, o Congresso Nacional elaborasse o Código de Defesa do Consumidor.

A elaboração de uma legislação específica para proteger o consumidor se faz mais do que necessária, pois, como bem observou José Geraldo de Britto Filomeno, um dos autores do anteprojeto do CDC, não se trata apenas de criar normas para amparar o consumidor, mas também de uma "política nacional de relações de consumo" (...) no sentido que se trata em última análise de uma "filosofia de ação", para harmonizar as relações de consumo. ${ }^{4}$

Dessa maneira, o CDC é uma lei com o escopo de colocar em prática o plano de proteção do consumidor feito pelo legislador e, ainda tem como fim a harmonização das relações consumeristas.

Assim, em meio a estes dispositivos constitucionais e infraconstitucionais, ficou claro o reconhecimento por parte do legislador acerca do

\footnotetext{
${ }^{3}$ BRASIL. Constituição da República Federativa do Brasil de 1988. Disponível em: <http://www.planalto.gov.br/ccivil_03/constituicao/constituicaocompilado.htm>. Acesso em: 21. Setembro. 2016.

${ }^{4}$ Cf. BENJAMIN, Antonio Herman V.; MARQUES, Cláudia Lima; BESSA, Leonardo Roscoe. Manual de Direito do Consumidor. $2^{\text {a }}$ edição revista, atualizada e ampliada. São Paulo: Revista dos Tribunais, 2009. p. 289.
} 
desequilíbrio existente nas relações de consumo e, mais ainda, a necessidade de proteção legal especial a uma das partes dessas relações, o consumidor.

\subsection{CONCEITO DE RELAÇÃO DE CONSUMO}

Em meio às diversas atividades que exercem grande influência na vida do homem está o comércio, uma das práticas mais remotas que foi se desenvolvendo de acordo com as necessidades do homem até atingir o cenário atual.

Dessas relações comerciais surgiram diversas ramificações, das quais merecem o devido destaque as relações de consumo regulamentadas pela Lei ${ }^{\circ}$ 8.078/90.

Apesar do Código regular essas relações, o legislador brasileiro em sua elaboração não definiu o que é relação de consumo, ficando a cargo da doutrina e da jurisprudência.

Rizzatto de forma simplificada entende que:

Haverá relação jurídica de consumo sempre que se puder identificar num dos polos da relação o consumidor, no outro, o fornecedor, ambos transacionando produtos e serviços. ${ }^{5}$

A relação de consumo tem como sujeitos o consumidor e o fornecedor, em posições antagônicas, e esta relação tem como propósito transacionar bens e serviços, nas formas de aquisição ou contratação visando à satisfação das necessidades do consumidor.

Dessa forma, havendo em um dos polos da relação o fornecedor, indivíduo que coloca no mercado de consumo bens e serviços, negociando estes, com o consumidor, parte vulnerável e hipossuficiente, que os adquirirá a fim de utilizá-los em proveito próprio restará caracterizada a relação de consumo.

\footnotetext{
${ }^{5}$ NUNES, Luis Antônio Rizzatto. Curso de direito do consumidor.7. ed. São Paulo: Saraiva, 2012, p. 120.
} 
Assim, a relação de consumo constitui um estreito vínculo entre o fornecedor e o consumidor, em que o primeiro, exercendo a atividade econômica com habitualidade, expõe seus produtos ou serviços no mercado, a fim de que o consumidor, seja pessoa física ou jurídica, mas vulnerável e hipossuficiente venha adquiri-los ou contratá-los buscando a satisfação de suas necessidades.

\subsection{SUJEITOS DA RELAÇÃO DE CONSUMO}

\subsubsection{Conceituação de consumidor}

É de fundamental importância para a compreensão de este trabalho conceituar quem poderá ser consumidor; engana-se quem conceitua o consumidor com base apenas na definição restritiva do artigo $2^{\circ}$, caput, do CDC: a sua conceituação é complementada pelo parágrafo único do referido artigo, bem como pelos artigos 17 e 29 do Código ${ }^{6}$. A fusão destes artigos tem como objetivo atingir um maior número de pessoas vulneráveis que estão expostas às práticas comerciais abusivas.

$\mathrm{O}$ artigo $2^{\circ}$, caput, do CDC traz a conceituação padrão, ou em sentido estrito de consumidor ao definir que são considerados consumidores todas as pessoas físicas ou jurídicas que adquirem ou utilizam produtos ou serviços como destinatário final. Ou seja, será consumidor o indivíduo que retira o produto do mercado de consumo seja adquirindo-o para si ou apenas utilizando-o, bem como aquele que coloca fim à cadeia de produção.

É importante destacar, como bem fez Claudia Lima Marques, que o indivíduo que utiliza o bem para continuar a produzir, não se encaixa no perfil protetivo da lei, pois ele não é o consumidor-final, já que ele está transformando o bem, utilizando o bem para oferecê-lo por sua vez ao cliente, seu consumidor ${ }^{7}$.

\footnotetext{
${ }^{6}$ Cf. NUNES, Luis Antônio Rizzatto. Curso de direito do consumidor - 7. ed. São Paulo: Saraiva, 2012, p. 120/121.

${ }^{7}$ Cf. MARQUES, Claudia Lima. Caso Teka vs. Aiglon: em defesa da teoria finalista de interpretação do art. $2^{\circ}$ do CDC. Revista dos Tribunais. Vol. 36, 2000. p. 221/240.
} 
Além disso, o parágrafo único deste artigo completa a definição dispondo que é equiparado ao consumidor, a coletividade de pessoas, mesmo que de pessoas indetermináveis, que tenham participado de alguma forma da relação de consumo. Esta equiparação trazida pela lei busca proteger também a coletividade de pessoas que tenham direitos ou interesses atingidos pela desobediência ao Código.

Não bastar isso, os artigos 17 e 29 complementam a definição do artigo $2^{\circ}$ ampliando o conceito de consumidor, a fim de atingirem mais pessoas em situação de vulnerabilidade.

$\mathrm{O}$ artigo 17 equipara a condição de consumidor a qualquer vítima do evento danoso que em razão de vícios de qualidade dos bens ou serviços, logo, o Código buscou proteger o consumidor que foi vítima de um acidente provocado pelo produto ou serviço defeituoso, mesmo que tal consumidor não tenha participado da relação de consumo seja adquirindo, ou utilizando o produto ou o serviço.

Por fim, o artigo 29 busca proteger todas as pessoas, mesmo que indetermináveis, que estejam expostas às práticas comerciais ou contratuais consideradas abusivas pelo Código. A proteção ampla e genérica do mencionado artigo é de fundamental importância na defesa do consumidor, primeiro porque como o artigo $2^{\circ}$ caput da lei refere-se apenas à proteção do consumidor quando da aquisição de produtos ou serviços, faz-se necessário oferecer proteção ao consumidor também antes da conclusão do negócio jurídico com o fornecedor; segundo, porque tem o alcance de proteger os consumidores de práticas abusivas mesmo que não tenham se relacionado diretamente com o fornecedor. Este cuidado da lei tem como fim resguardar toda a coletividade que possa ser submetida a práticas abusivas, como é caso da veiculação de publicidade enganosa ou abusiva.

Dessa forma, a lei consumerista procurou tutelar aqueles indivíduos que reunissem certas condições subjetivas, que evidenciam sua condição de vulnerabilidade ante o mercado de consumo. Graças à especificidade da lei, foi possível oferecer uma proteção mais precisa às necessidades desses indivíduos.

Dentro deste tópico, é imprescindível abordar a teoria da vulnerabilidade aplicada às relações de consumo.

Trata-se de uma das mais importantes teorias aplicadas às relações de consumo e, é analisada por meio da conceituação de consumidor. O Código Consumerista foi criado com o escopo de proteger um indivíduo específico, o consumidor, pois claramente este está no polo mais fraco da 
relação de consumo e por isso, merece proteção especial para que seja atenuado o desequilíbrio natural decorrente desta relação.

A importância de se proteger o consumidor se sustenta na necessidade que ele tem de ser protegido, pois se fragiliza em seu poder de negociação, o que leva à necessidade de coibir práticas ilícitas resultantes de um sistema econômico competitivo, que nem sempre respeita os valores éticos, causando vários danos ao consumidor, no que diz respeito a sua vida, privacidade e interesses econômicos ou outros bens ${ }^{8}$.

Em vista deste desequilíbrio presente na relação de consumo, em que o consumidor é colocado e situação desfavorável em relação ao fornecedor, surgiu a teoria da vulnerabilidade.

A teoria da vulnerabilidade constitui na percepção de que o consumidor é o elo mais frágil da relação de consumo, pois não detém o controle dos meios de produção e assim, é submetido às práticas comerciais impostas pelos fornecedores.

Para a correta aplicação desta teoria, deve ser realizada uma interpretação em concomitante com o princípio da igualdade, previsto o art. $5^{\circ}$ caput da $\mathrm{CF}$.

Ao realizar a análise em conjunto destes institutos, o intérprete deve efetuar um balizamento do princípio da igualmente, utilizando-se de instrumentos que beneficiem o consumidor, parte mais frágil, buscando atingir uma isonomia plena entre ele e o fornecedor.

Nesse sentido, Fabrício Bolzan, em sua obra, aduz que a teoria da vulnerabilidade faz uma diferenciação ou a discriminação (positiva) entre as partes objetivando alcançar a igualdade ${ }^{9}$.

Assim, devido a este desequilíbrio existente entre os contraentes, a teoria da vulnerabilidade surgiu como instrumento para reduzir essa assimetria e alcançar a igualdade entre as partes.

Desse modo, esta teoria foi o ponto de partida para colocar consumidor e fornecedor em igualdade e, para isso foi necessário proteger o consumidor de forma especial para que esta isonomia fosse alcançada.

Frente a todo o exposto, o reconhecimento da vulnerabilidade do consumidor justifica a sua proteção especial no mundo jurídico que tem

\footnotetext{
${ }^{8}$ Cf. CARVALHO, Kildare Gonçalves. Direito constitucional. 15. ed. rev., atual. e ampl. Belo Horizonte: Del Rey, 2009. p. 728.

${ }^{9}$ Cf. BOLZAN, Fabrício. Direito do consumidor esquematizado. 2. ed. São Paulo: Saraiva, 2014, p. 195.
} 
como fim protegê-lo e colocá-lo em situação de equiparação ao fornecedor, para que seus direitos sejam resguardados e os deveres do fornecedor cumpridos.

\subsubsection{Destinatário final}

Inicialmente cumpre pontuar que a expressão destinatário final, está inserida dentro da conceituação de consumidor no art. $2^{\circ}$ do CDC. A referida expressão gera grande divergência na doutrina, visto que há diferentes ângulos de interpretação e, ainda diversas correntes que tentam esclarecer o significado dessa expressão, porém, em meio a esse caos dois enfoques e duas correntes se destacam quanto ao tema, sendo eles respectivamente os enfoques fático e econômico e as correntes maximalista e finalista.

Inicialmente, o primeiro ângulo de interpretação entende que destinatário final é o consumidor que retirar o bem ou serviço do mercado adquirindo-o ou utilizando-o, assim recebeu a denominação de destinatário final fático. Já o segundo entende que destinatário final é o consumidor que coloca fim à cadeia de produção, sendo titulado de destinatário final econômico. ${ }^{10}$

Tais apontamentos têm forte ligação com a corrente finalista mitigada, pois como exposto adiante, eles são utilizados pelo STJ como parâmetro para aplicar-se a referida teoria a casos específicos.

Feita esta ponderação, será feita a análise das correntes doutrinárias.

A teoria maximalista defende que tal expressão deve ser interpretada da forma mais ampla possível, para que possa atingir o maior número de relações jurídicas. Para seus adeptos, são abrangidos qualquer tipo de consumidor que adquire ou utiliza o produto ou serviço em proveito próprio ou com a finalidade lucrativa. ${ }^{11}$

${ }^{10}$ Cf. BOLZAN, Fabrício. Direito do consumidor esquematizado - 2. ed. São Paulo: Saraiva, 2014, p. 64.

${ }^{11} \mathrm{Cf}$. BOECHAT, Marcos. O conceito de destinatário final para fins de aplicação do CDC. Disponível em <http://www.esinf.com.br/texto-de-apoio-detalhes/?id=5>. Acesso em: 20. Setembro. 2016. 
Já para os defensores da teoria finalista, a expressão "destinatário final" deve ser interpretada de forma restritiva, tendo como base a questão econômica da aquisição do produto ou serviço. Dessa forma, se o agente utilizar o produto com a finalidade lucrativa, dando continuidade à cadeia econômica, não se enquadrará na conceituação de consumidor, exceto se utilizar o bem para consumo próprio. ${ }^{12}$

Ambas as correntes são duramente criticadas: a primeira é considerada demasiadamente abrangente, pois se considerar que todos os agentes da cadeia de produção sejam consumidores isto acabaria contrariando os fins do próprio CDC que como norma de proteção especial, visa salvaguardar os consumidores vulneráveis e hipossuficientes. A segunda, ao contrário da primeira, é criticada por ser excessivamente restritiva, uma vez que por meio desse panorama muitas pessoas ficariam excluídas dos benefícios da lei consumerista como os profissionais liberais e as empresas de pequeno porte. ${ }^{13}$

Em meio a esta discussão, o STJ criou uma corrente intermediária, a teoria finalista mitigada, que leva em conta dois fatores: a destinação do produto ou serviço adquirido, bem como o poder econômico por parte do consumidor. ${ }^{14}$

Esta teoria é fundamentada no artigo $4^{\circ}$, I da lei consumerista que reconhece em determinados e específicos casos a vulnerabilidade da pessoa jurídica em relação à outra parte contratante, mesmo que tenha ela adquirido o produto ou serviço no curso do desenvolvimento da atividade empresarial. $^{15}$

Observa-se que entendimento do E. Tribunal é resultado de uma interpretação teleológica do art. $2^{\circ}$ atrelada à análise finalística do art. 4 , inciso I, ambos do CDC.

${ }^{12}$ Cf. BOECHAT, Marcos. O conceito de destinatário final para fins de aplicação do CDC. Disponível em <http://www.esinf.com.br/texto-de-apoio-detalhes/?id=5>. Acesso em: 20. Setembro. 2016.

13 Ibidem.

${ }^{14}$ SILVA, Hugo Alves da. Destinatário final. Disponível em: <http://hugosilva.jusbrasil.com.br/artigos/221239377/destinatario-final>. Acesso em: 25. Julho. 2016.

15 BRASIL. Superior Tribunal de Justiça. Recurso Ordinário no 27512 BA (2008/0157919-0). Recorrente: Banco Safra S/A. Recorrido: Plascalp Produtos Cirúrgicos LTDA. Relatora: Ministra Nancy Andrighi. Brasília, 20 de agosto de 2009. Disponível em <http://stj.jusbrasil.com.br/jurisprudencia/6031597/recurso-ordinario-em-mandado-de-seguranca-rms-27512-ba-2008-0157919-0>. Acesso em: 07. Julho. 2015. 
A Ministra Nancy Andrighi, principal percursora desta corrente no STJ, em sede de Recurso Especial sintetiza o tema de forma clara e objetiva:

CONSUMIDOR. DEFINIÇÃO. ALCANCE. TEORIA FINALISTA. REGRA. MITIGAÇÃO. FINALISMO APROFUNDADO. CONSUMIDOR POR EQUIPARAÇÃO. VULNERABILIDADE.

3. A jurisprudência do STJ, tomando por base o conceito de consumidor por equiparação previsto no art. 29 do CDC, tem evoluído para uma aplicação temperada da teoria finalista frente às pessoas jurídicas, num processo que a doutrina vem denominando finalismo aprofundado, consistente em se admitir que, em determinadas hipóteses, a pessoa jurídica adquirente de um produto ou serviço pode ser equiparada à condição de consumidora, por apresentar frente ao fornecedor alguma vulnerabilidade, que constitui o princípio-motor da política nacional das relações de consumo, premissa expressamente fixada no art. $4^{\circ}$, I, do CDC, que legitima toda a proteção conferida ao consumidor. ${ }^{16}$

Por meio desta perspectiva o STJ acabou ressaltando a figura dos consumidores-equipados, que são as pessoas físicas ou jurídicas que preenchem os requisitos objetivos do conceito do art. $2^{\circ}$, bem como o requisito subjetivo (vulnerabilidade), embora não preencham a qualidade de destinatário final econômico do produto ou serviço.

Em meio a esta ampla discussão, tanto doutrinária como jurisprudencial, certamente a teoria finalista mitigada é a mais coerente a ser aplicada neste momento, pois o conceito de destinatário final não está adstrito apenas à letra do artigo, sendo ele determinado com base nos princípios constitucionais, bem como de acordo com a análise do caso contrato.

16 BRASIL. Superior Tribunal de Justiça. Recurso Especial $\mathbf{n}^{\mathbf{0}}$ 1.195.642-RJ (2010/0094391-6). Recorrente: Empresa Brasileira de Telecomunicações S/A Embratel. Recorrida: Juleca 2003 Veículos LTDA. Relatora: Ministra Nancy Andrighi. Brasília, 13 de novembro de 2012. Disponível em: <https://ww2.stj.jus.br/processo/revista/inteiroteor/?num_registro=201000943916\&dt_publicacao=21/11/2012 >. Acesso em: 01. Agosto. 2016. 


\subsubsection{Conceituação de fornecedor}

O termo fornecedor apresenta-se de forma genérica e tem como espécies o fabricante, o produtor, o construtor, o importador e o comerciante que podem ser pessoas físicas, jurídicas ou entes despersonalizados. Todos eles têm como característica em comum, o fato de ofertarem seus produtos ou serviços no mercado de consumo com o objetivo de atender às necessidades dos consumidores.

A partir dessa definição geral de que o fornecedor oferta seus produtos ou serviços no mercado consumerista com o fim de satisfazer as necessidades dos consumidores surge uma dúvida: o fornecedor necessariamente deve exercer tal atividade com profissionalismo para se enquadrar no conceito legal de fornecedor, ou é necessário apenas o exercício destas atividades com habitualidade?

No que toca tal discussão a doutrina não tem um posicionamento unânime.

Claudia Lima Marques, ao se posicionar sobre o tema, faz distinção entre o fornecedor de produtos e o fornecedor de serviços.

Para a citada Autora, o fornecedor de produtos tem como característica o desenvolvimento de atividades tipicamente profissionais, como é o caso da comercialização, produção e importação, devendo haver também no exercício de tais atividades habitualidade. Quanto ao fornecedor de serviços, entende ser necessário apenas o exercício da atividade de forma habitual ou reiterada. ${ }^{17}$

Já Fabrício Bolzan entende que o CDC em seu art. $3^{\circ}$ ao conceituar fornecedor não fez qualquer exigência em relação à presença do requisito do profissionalismo. Todavia, quanto à habitualidade, sustenta que este requisito é inerente à conceituação de fornecedor tanto a pessoa física, como pessoa jurídica, em especial quanto a esta última, quando exerce a atividade-fim.

${ }^{17}$ Cf. MARQUES, Claudia Lima. Contratos no Código de Defesa do Consumidor - O novo regime das relações contratuais $-7^{a}$ ed. São Paulo: Revista dos Tribunais, 2014, p. 416. 
Nesse sentido, para este Autor, o requisito do profissionalismo seria um plus em relação à habitualidade e que esta seria suficiente para identificar o fornecedor como sujeito da relação jurídica de consumo. ${ }^{18}$

O Autor ainda vai além: conclui que se considerado o requisito do profissionalismo como essencial ao conceito de fornecedor, automaticamente estariam excluindo as pessoas físicas deste conceito. ${ }^{19}$

Ante esta divergência de pensamentos, crê-se que o requisito da habitualidade deve estar presente no conceito de fornecedor em qualquer de suas ramificações, pois a habitualidade pode ser um dos modos de se identificar um fornecedor tipificado no CDC de um mero fornecedor esporádico.

Portanto, não há dúvidas de que o requisito da habitualidade é inerente a todas as categorias de fornecedores enquadrados no CDC.

Superada essa questão, um ponto importante a ser ressaltado refere-se à questão da remuneração indireta nos contratos de consumo eletrônicos.

Primeiramente, cumpre conceituar o que é remuneração direta.

A remuneração direta é a retribuição paga pelo consumidor ao fornecedor em virtude da aquisição de produtos ou pela contratação de serviços. O pagamento é realizado pelos meios tradicionais como em dinheiro, em cartões de crédito ou débito, por meio de cheques etc.

A remuneração indireta consiste em uma das formas de pagamento em que o fornecedor recebe outras vantagens diversas do pagamento direto.

Aplicando-se a remuneração indireta aos contratos de consumo eletrônicos, verifica-se que o envio de produtos através da internet ou fornecimento de serviços ao consumidor, sem solicitação prévia, considera-se caso ocorra, como sendo amostra grátis, não sendo ele obrigado a pagar ${ }^{20}$.

Nestas hipóteses, os fornecedores com fins lucrativos que ofertam produtos ou serviços gratuitos acabam recebendo vantagem diversa do pagamento direto, geralmente a sua remuneração está embutida em outros

${ }^{18}$ Cf. BOLZAN, Fabrício. Direito do consumidor esquematizado. 2. ed. São Paulo: Saraiva, 2014, p. 98/99.

${ }^{19}$ Ibidem.

${ }^{20}$ Cf. MOREIRA, M. E. S. Comércio Eletrônico: a aplicação do direito do consumidor aos contratos de comércio eletrônico. 2010. 74 f. Trabalho de Conclusão de Curso - Centro Universitário de Brasília, Brasília. 2010, p. 27. 
produtos ou serviços disponibilizados no site ou simplesmente buscam a divulgação de uma marca ou produto.

Frente a tudo isso, conclui-se que são fornecedores tanto as pessoas físicas ou jurídicas, como os entes despersonalizados que exercem suas atividades de fornecimento de produtos ou prestação de serviços mediante remuneração, com certa habitualidade e com o fulcro de satisfazer as necessidades dos consumidores.

\section{CONSIDERAÇÕES GERAIS ACERCA DA INTERNET E O COMÉRCIO ELETRÔNICO}

\subsection{CONCEITO E FUNCIONAMENTO DA INTERNET}

No Brasil, o conceito de internet foi estabelecido na Norma $n^{\circ}$ 004/95 publicada pelo Ministério das Comunicações que conceitua:

Internet é o nome genérico que designa o conjunto de redes, ou meios de transmissão e comutação, roteadores, equipamentos e protocolos necessários à comunicação entre computadores, bem como o "software" e os dados contidos nestes computadores. $^{21}$

Dessa forma, a internet caracteriza-se por ser um instrumento de comunicação que por meio de computadores interligados, seus usuários trocam informações em tempo real, não pertencendo a qualquer pessoa, empresa ou ente estatal, bem como não havendo qualquer autoridade central que a regulamente, havendo apenas comitês gestores, que objetivam coordenar serviços, todavia estão sempre limitados a evolução técnica.

\footnotetext{
${ }^{21}$ BRASIL. Norma 004/95 (Uso de meios da rede pública de telecomunicações para acesso à internet). Disponível em: <http://www.anatel.gov.br/hotsites/Direito_Telecomunicacoes/TextoIntegral/ANE/prt/minicom_19950531_148.pdf $>$. Acesso em 22. Setembro.2016.
} 
Quanto ao seu funcionamento, atualmente consiste na interligação de computadores configurados atuando como servidores, que hospedam arquivos em um formato livre para que possam ser visualizados pelos usuários que estão conectados, através de páginas de internet, programas de comunicação instantânea e outras diversas ferramentas.

A conexão de um usuário é realizada através do provedor de internet que, ao se conectar, recebe um endereço dado por este, sendo denominado IP, que é representado em um formato numérico que pode identificar de onde está sendo realizado o acesso.

Hoje, há a possibilidade de qualquer pessoa física ou jurídica participar da internet, bastando para isso ter um computador que possua uma conexão ao telefone, um software que permita o acesso, além de um provedor de internet.

À vista disso tudo, depreende-se que a expansão da internet em todo o mundo associada à facilidade de acesso pelo público em geral, foram fatores que juntos resultaram em um grande impacto na sociedade, pois, cada vez mais, quebram-se as barreiras entre ideias, pensamentos e cultura, isto porque cada usuário transmite e absorve conteúdos nunca antes conhecidos, surgindo aí novas figuras que atingiram todo o escopo jurídico como o comércio eletrônico, resultando no surgimento de novas empresas, novos tipos de crimes e criminosos, enfim, um novo modo de vivência social.

No Brasil, a internet foi inicialmente divulgada como meio de informação, haja vista que os primeiros sites brasileiros eram voltados para a divulgação de notícias. Posteriormente, foram criados sites de compras, pesquisa e entretenimento.

A rápida evolução e a possibilidade de ganhar dinheiro dentro deste mercado despertaram o interesse de diversas áreas, e uma delas foi a comercial, que atraiu diversas empresas para comercializassem seus produtos via web, tal ação teve um retorno bastante positivo, pois a cada dia mais consumidores passaram a utilizá-la como principal meio de aquisição de bens de consumo, em razão de sua facilidade e comodidade.

Desse modo, percebe-se que, neste curto período, a internet se desenvolveu em um ritmo frenético até os dias atuais, havendo ainda grandes expectativas acerca da continuidade de seu avanço e crescimento em razão da globalização. 


\subsection{O MARCO CIVIL DA INTERNET}

A mais nova legislação sobre o uso da internet no Brasil foi publicada recentemente por meio da Lei $\mathrm{n}^{\circ}$. 12.965/14 que ficou conhecida como o Marco Civil da Internet. Todavia, tal tema já vinha sendo debatido desde 2009.

A nova lei compilou em seu texto legal, princípios, garantias, direitos e deveres dos usuários, além de dispor acerca da atuação do Estado com a finalidade de estabelecer mais clareza e segurança no que está sendo disponibilizado por meio da rede.

Assim, estabeleceram-se como pontos centrais a neutralidade da rede, os direitos do usuário na rede, a privacidade na internet, a responsabilização do conteúdo ali divulgado, bem como a responsabilidade do Estado.

É evidente, portanto, a grande influência que essa nova legislação exerce sobre o Comércio Eletrônico.

Inicialmente, o princípio da neutralidade da rede, que permeia todo o texto da lei, assegura aos usuários e obriga os fornecedores que ofertam serviços de internet tratamento igualitário, sem qualquer distinção dos dados que circulam pela rede, seja ela por conteúdo, origem, destino ou serviço. Obriga os fornecedores a manterem a qualidade dos serviços contratados.

Merece a referida lei, que dispõe acerca dos direitos e garantias dos usuários da rede, dentre eles a proteção à privacidade do usuário que está intimamente ligada à segurança dos dados, pois, a partir da análise conjunta deles, a lei conclui que os fornecedores que possuam os dados dos usuários não poderão repassá-los a terceiros para fins comerciais sem o consentimento livre e expresso do usuário. ${ }^{22}$

Além disso, uma das grandes inovações que a lei dispõe se refere à responsabilização dos próprios usuários pelo conteúdo que publicam na rede. Na prática, essa medida isenta os provedores, sites e aplicativos de responsabilidade.

${ }^{22}$ Cf. O marco civil da internet entra em vigor. Disponível em: <http://culturadigital.br/marcocivil/>. Acesso em: 01. Junho. 2015. 
Nesse sentido, para que conteúdos impróprios sejam retirados da rede, é necessária a autorização judicial. Todavia, caso o provedor não retire o conteúdo, ou seja, não atenda à determinação, poderá ele ser responsabilizado por perdas e danos.

Diante das inovações trazidas pelo Marco Civil, é possível concluir que ele regulamenta não só o Comércio Eletrônico como também a utilização da rede em termos gerais.

\subsection{O COMÉRCIO ELETRÔNICO}

As relações comerciais, ao longo de centenas de anos, desenvolveram-se tomando diversas facetas até chegarem ao cenário atual.

Hoje em dia, com o aperfeiçoamento das tecnologias de informação, o comércio consolidou-se em um processo de troca dinâmico atingindo patamares extraordinários.

Para que tal fenômeno ocorresse, alguns motivos desencadearam sua grande expansão, um deles em especial foi o início das relações comerciais por meio da internet, ou seja, o comércio eletrônico.

\subsubsection{Conceito}

Genericamente, o comércio eletrônico configura-se como sendo a junção de todos os processos envolvidos na cadeia de valor realizada em um ambiente virtual, por meio da utilização de ferramentas com grande tecnologia de informação e de comunicação, objetivando atender às necessidades exigidas pelos negócios. Pode-se realizar de forma completa ou parcial, tipificando-se por transações Negócio-Negócio - Business to Business (B2B); Negócio-Consumidor - Business to Consumer (B2C); Consumidor - Consumidor - Consumer to Consumer (C2C); Governo Consumidor - Government to Citizen (G2C); e Governo Negócio - Government to Business (G2B) que serão oportunamente analisadas uma a uma. 
Cláudia Lima Marques, considerando a definição de comunicações comerciais trazida pelo art. $2^{\circ}$ da Diretiva 2000/31/CE (União Européia ${ }^{23}$, faz importante distinção entre comércio eletrônico stricto sensu e comércio eletrônico lato sensu.

Podemos definir comércio eletrônico de uma maneira estrita, como sendo uma das modalidades de contratação não presencial ou à distância para a aquisição de produtos e serviços através do meio eletrônico ou via eletrônica. De maneira ampla, podemos visualizar o comércio eletrônico como um novo método de fazer negócios através de sistemas e redes eletrônicas ${ }^{24}$.

Dessa forma, a autora, ao conceituar o comércio eletrônico de forma ampla, lato senso, abrangeu todas as formas de transações ou troca de informações comerciais remetendo assim, à existência de todas as fases contratuais na relação estabelecida entre o consumidor e o fornecedor ${ }^{25}$.

Assim pode-se concluir que o comércio eletrônico se refere a realizar transações por meio de computadores e comunicação de dados. Consiste na realização de toda a cadeia de valor dos processos de negócio num ambiente eletrônico, através da aplicação intensa de tecnologias de comunicação e de informação, atendendo aos objetivos de compra e venda de informações, produtos e serviços.

3 OS CONTRATOS DE CONSUMO ELETRÔNICOS

\subsection{CONCEITO DE CONTRATO DE CONSUMO ELETRÔNICO}

${ }^{23}$ Cf. MARQUES, Cláudia Lima. Confiança no comércio eletrônico e a proteção do consumidor. São Paulo: Revista dos Tribunais, 2004, p. 38/39.

${ }^{24}$ Ibidem.

${ }^{25}$ Ibidem. 
Inicialmente, antes de conceituarmos o que seja o contrato de consumo eletrônico, é necessário realizar construções conceituais acerca de seus termos para chegar à definição do que é o contrato de consumo eletrônico.

O conceito de contrato é simples e objetivo. Carlos Roberto Gonçalves, em sua obra, ressalta a conceituação sucinta de Clóvis Bevilacqua: para o Autor, o contrato constitui um "acordo de vontades para o fim de adquirir, resguardar, modificar ou extinguir direitos" $" 26$.

A relação de consumo é aquela em que se constitui um vínculo entre o fornecedor e o consumidor, em que o primeiro expõe seus produtos ou serviços no mercado consumerista, a fim de que um consumidor seja pessoa física ou jurídica, mas vulnerável e hipossuficiente adquira-os buscando a satisfação de suas necessidades.

Aquisição de produtos ou contratação de serviços pela via eletrônica é aquela formalizada pela rede mundial de computadores, a internet.

Reunindo tais conceitos e aplicando-os à formalização de contratos por meio da internet, conclui-se que o contrato de consumo eletrônico é o acordo de vontades firmado entre o consumidor e o fornecedor por meio da internet com o fulcro de que o primeiro adquira produtos ou serviços do segundo como destinatário final.

\subsection{REQUISITOS PARA A SUA FORMAÇÃO}

Como já explanado, os requisitos para a formação do contrato de consumo eletrônico são idênticos aos dos contratos tradicionais, em ambas as modalidades para que o contrato tenha validade juridicamente é necessário o preenchimento dos requisitos do art. 104 e incisos do CC.

Este artigo do Código Civil elenca três requisitos a serem satisfeitos que serão analisados sucintamente.

Primeiramente, é necessário que os contratantes sejam capazes, ou seja, sejam pessoas que, por si só, possam exercer os atos da vida civil ${ }^{27}$.

\footnotetext{
${ }^{26}$ Cf. LENZA, Pedro. (Org.). Direito Civil 1 Esquematizado. $2^{\text {a }}$ ed. São Paulo: Saraiva, 2012, p. 705.

${ }^{27}$ Cf. MACHADO, Antônio Cláudio da Costa. Código Civil Interpretado artigo por artigo, parágrafo por parágrafo. $7^{\mathrm{a}} \mathrm{ed}$. Barueri: Manole, 2014, p 139.
} 
Na sequência, o objeto da contratação deve ser lícito, possível, determinado ou determinável.

O objeto lícito é aquele que está de acordo com a ordem jurídica e moral, bem como segundo os bons costumes, uma vez que, sendo ilícito o objeto, o contrato será declarado nulo conforme o art. 166, II do CC.

Quanto à possibilidade do objeto, é aquela que está ligada aos planos físico e jurídico. No plano físico, é verificada a viabilidade de se tornar a contratação efetiva no mundo. Já no plano jurídico, é verificada a legalidade da contratação, se ela está em conformidade com o ordenamento jurídico.

Em relação à determinação do objeto do contrato pode ser determinado ou determinável. O primeiro é o objeto previamente descrito, qualificado e individualizado no início do contrato. Já o segundo trata-se do objeto a ser individualizado futuramente pelos contraentes até o momento da execução do contrato.

Por fim, a lei civil prevê que o contrato deve ser celebrado de acordo a forma prescrita pela lei ou que não seja proibido por ela.

Cumpre advertir que, em regra, a forma de contratação é livre (art. 107 do CC), porém em algumas modalidades o legislador previu a observância a alguma forma para dar maior segurança jurídica ao negócio a ser celebrado.

A violação de qualquer dos requisitos para formalização do contrato leva à decretação de nulidade do contrato conforme o art. 166 e incisos do CC.

À vista disso, fica claro que os requisitos para formalização do contrato de consumo eletrônico são os mesmos exigidos para os contratos tradicionais e tais requisitos devem ser observados pelas partes contratantes, sob pena de nulidade da convenção.

\subsection{O DECRETO № 7.962/2013}

Antes da entrada em vigor do Decreto $n^{\circ} 7.962 / 13$ não havia normas além do CDC que regulamentassem os contratos no comércio eletrônico nas relações de consumo.

Com a entrada no ordenamento jurídico, o Decreto abordou aspectos importantes como o dever dos fornecedores prestarem informações 
claras e precisas acerca do produto ou serviço colocado no mercado de consumo, dever de facilitarem o atendimento do consumidor e por fim, de respeitarem o direito de arrependimento.

Neste panorama, foram fixadas medidas para que tais deveres sejam cumpridos pelos fornecedores, entre elas a obrigação dos fornecedores de disponibilizarem em seus sites em local de destaque e de fácil visualização, o nome empresarial e número de inscrição no Cadastro Nacional de Pessoas Físicas ou no Cadastro Nacional de Pessoas Jurídicas do Ministério da Fazenda. Além disso, os fornecedores devem prezar pela manutenção de serviço adequado e eficaz de atendimento em meio eletrônico, que possibilite ao consumidor a resolução de demandas referentes à informação, dúvida, reclamação, suspensão ou cancelamento do contrato e, ainda obriga os fornecedores a rescindirem eventuais contratos acessórios, sem qualquer ônus ao consumidor quando ele tiver exercido o direito de arrependimento.

Além de reforçar as normas do CDC, o citado Decreto veio como instrumento de inovação, pois disciplina pela primeira vez regras específicas acerca das ofertas nas compras coletivas (art. $\left.3^{\circ}\right)^{28}$ e, ainda determina que os fornecedores devam comunicar às administradoras de cartão de crédito, quando o direito de arrependimento for exercido, para que não efetuem o lançamento da venda na fatura do consumidor ou que seja realizado o estorno do valor caso o lançamento já tenha ocorrido (art. $5^{\circ}, \S 3^{\circ}$ incisos).

Portanto, depreende-se que o Decreto apresenta conteúdo de grande relevância no mundo jurídico, pois além de reforçar algumas normas do CDC aborda temáticas que não tinham previsão legal específica.

\subsection{PROTEĈ̃̃ COLETIVA DOS CONSUMIDORES NA RELAÇẨO DE CONSUMO ELETRÔNICA}

\footnotetext{
${ }^{28}$ Cf. Art. $3^{\text {o }}$. Os sítios eletrônicos ou demais meios eletrônicos utilizados para ofertas de compras coletivas ou modalidades análogas de contratação deverão conter, além das informações previstas no art. 2o, as seguintes:

I - quantidade mínima de consumidores para a efetivação do contrato;

II - prazo para utilização da oferta pelo consumidor; e

III - identificação do fornecedor responsável pelo sítio eletrônico e do fornecedor do produto ou serviço ofertado, nos termos dos incisos I e II do art. 2o.
} 
As relações de consumo formalizadas por meio comércio eletrônico que abordam interesses difusos, coletivos ou transindividuais também são protegidas pelo CDC.

A justificativa para a proteção destas relações que versam acerca de tais interesses se dá na necessidade de amparar estes consumidores que contratam pela internet e são expostos à excessiva situação de vulnerabilidade frente aos fornecedores ${ }^{29}$.

Por conta desta modalidade de contratação, estes consumidores acabando sendo expostos com maior intensidade às práticas abusivas dos fornecedores.

Portanto, frente a esta situação é crucial que a proteção coletiva dos consumidores seja difundida e realizada para adequado amparo desses consumidores.

\subsection{AS CLÁUSULAS ABUSIVAS E A SUA ANULAÇÃO FRENTE ÀS RELAÇÕES DE CONSUMO ELETRÔNICAS}

O aprimoramento das formas de contratação atingiu patamares nunca antes imaginados pelo homem; há 150 (cento e cinquenta) anos, não se imaginava firmar contratos em larga escala. Hoje, com os contratos de adesão, essa contratação se tornou possível.

Embora os contratos de adesão tenham alavancado as contratações, nem tudo que surgiu a partir de então foram benefícios para ambos os contratantes. Foi por meio desses contratos que o consumidor se tornou excessivamente vulnerável às práticas comerciais dos fornecedores por conta da presença das cláusulas abusivas inseridas nestes contratos.

Inicialmente, para verificar se uma cláusula é abusiva, é necessário analisá-la sob o ângulo da boa-fé objetiva, não havendo espaço para a sua acepção subjetiva, já que a sua caracterização independe de análise

\footnotetext{
${ }^{29}$ Cf. LIMA, Maria Renata Barros de. A vulnerabilidade do consumidor no e-commerce. Disponível em: <https://jus.com.br/artigos/24601/a-vulnerabilidade-do-consumidor-no-ecommerce>. Acesso em: 20. Setembro. 2016.
} 
subjetiva da conduta do fornecedor, se houve ou não malícia, intuito de obter vantagem indevida ou exagerada ${ }^{30}$.

Desse modo, a abusividade da cláusula deve ser verificada analisando-a sob a luz do princípio da boa-fé objetiva, que é um dos princípios basilares do CDC previsto no art. $4^{\circ}$, III, pouco importando para sua caracterização se o fornecedor agiu com dolo (má-fé).

Logo, as cláusulas abusivas caracterizam-se por serem aquelas impostas unilateralmente pelo fornecedor e que apresentam um conteúdo que gera desigualdade entre as partes, ou seja, acarreta um desequilíbrio na relação contratual e expõe o consumidor à situação de vulnerabilidade muitas vezes onerando-o excessivamente.

Nesse sentido, compreende-se que as cláusulas abusivas são inseridas durante a formação do contrato, especificamente na fase pré-contratual, em que são definidos os direitos do consumidor e os deveres do fornecedor. Porém, é no momento da execução do contrato que tais cláusulas começam a surtir seus efeitos.

O CDC, em seu art. 51, prevê algumas das hipóteses em que a cláusula será considerada abusiva, algumas porque o legislador ao inserir a expressão "entre outras" abriu margem para novas possibilidades de incidência de cláusulas abusivas, logo, o rol disposto no referido artigo é meramente exemplificativo.

Cláudia Lima Marques destaca que o que há de comum nessas cláusulas é o fato de não terem sido elaboradas com o fulcro de realizarem o justo equilíbrio nas obrigações das partes - ao contrário, destinam-se a reforçar a posição econômica e jurídica do fornecedor que as elabora ${ }^{31}$.

Assim é comum que tais cláusulas visem garantir vantagens apenas para o fornecedor que as elaborou; em decorrência disso, pode ocasionar a diminuição de seus deveres em relação aos consumidores ou até mesmo a exoneração de certas responsabilidades.

Para coibir a prática destas condutas abusivas nos contratos, o CDC impõe como sanção a nulidade de pleno direito dessas cláusulas, ou

\footnotetext{
${ }^{30}$ Cf. SOUZA, Maria Carolina Rosa de. Cláusulas contratuais abusivas nos contratos de consumo. Disponível em: <http://www.ambito-juridico.com.br/site/index.php?n_link=revista_artigos_leitura\&artigo_id=11277> Acesso em: 04. Junho. 2016.

${ }^{31}$ Cf. MARQUES, Claudia Lima. Contratos no Código de Defesa do Consumidor - O novo regime das relações contratuais. $7^{\mathrm{a}}$ ed. São Paulo: Revista dos Tribunais, 2014, p. 161.
} 
seja, a possibilidade de decretação de nulidade absoluta, seja a requerimento da parte, seja de oficio pelo juiz ${ }^{32}$.

Desse modo, sendo causa de nulidade absoluta, depreende-se que as cláusulas abusivas não podem se validar, pois segundo Nelson Nery Junior, tais cláusulas são nulas de pleno direito porque contrariam a ordem pública de proteção ao consumidor ${ }^{33}$.

Nesse sentido, não havendo a possibilidade de convalidação da cláusula, o contrato, em regra, não poderá ser declarado nulo como um todo, já que apenas uma ou alguns cláusulas estão maculadas. Dessa maneira, a solução é declarar a nulidade da cláusula abusiva, afastando-a da interpretação do contrato.

Porém, como pontuado, como exceção a essa regra, o contrato poderá ser declarado inteiramente nulo quando, ao se declarar a nulidade de determinada cláusula, a interpretação de o contrato resultar a qualquer das partes onerosidade excessiva em virtude da falta da referida cláusula. Assim, a melhor alternativa nesses casos é a decretação da nulidade do contrato completo.

Abordando-se a temática às relações de consumo eletrônicas, nota-se que os contratos de adesão são predominantes nesta modalidade de contratação e, como já abordado, nesses casos o consumidor apenas adere aos termos fixados pelo fornecedor e muitas vezes acaba submetido às cláusulas abusivas inseridas no contrato pelo fornecedor.

Desse modo, a referida modalidade de contratação, atrelada à inserção de cláusulas abusivas no contrato são circunstâncias que evidenciam a situação de vulnerabilidade a que o consumidor será exposto.

Portanto, diante do exposto, percebe-se que a figura das cláusulas abusivas é um dos vilões que o CDC vem tentando vencer, pois elas vão totalmente contra as disposições consumeristas e acentuam ainda mais o desequilíbrio existente nas relações de consumo.

\footnotetext{
${ }^{32}$ Cf. SOUZA, Maria Carolina Rosa de. Cláusulas contratuais abusivas nos contratos de consumo. Disponível em: <http://www.ambito-juridico.com.br/site/index.php?n_link=revista_artigos_leitura\&artigo_id=11277>. Acesso em: 03. Junho. 2016.

${ }^{33}$ Cf. NERY JR., Nelson. Código brasileiro de defesa do consumidor: comentado pelos autores do anteprojeto. p. 10. ed. Rio de Janeiro: Forense, 2011. v. I, p. 536-537.
} 


\subsection{O DIREITO DE ARREPENDIMENTO NAS RELAÇÕES CONSUMERISTAS POR MEIO DA INTERNET}

Muitas vezes, o consumidor, ao realizar compras fora do ambiente físico, vê-se cercado por um mar de ofertas contendo diversos produtos e serviços a sua disposição, e por tantas vezes bastam alguns cliques para ter seu desejo satisfeito.

Ocorre que, em muitas destas ocasiões, o consumidor acaba sendo exposto a técnicas agressivas de vendas ${ }^{34}$, tal fator associado ao seu desconhecimento do produto ou do serviço geralmente acarreta seu arrependimento em ter formalizado determinado contrato.

Com o fulcro de proteger o consumidor destes percalços, é aplicável o art. 49 do CDC. A referida norma prevê a possibilidade de desistência da contratação se o contrato foi firmado fora do estabelecimento comercial, fixando-se assim determinado prazo para a manifestação deste direito.

A partir da redação do dispositivo, depreende-se que a intenção do legislador foi de conceder ao consumidor um prazo razoável para reflexão acerca da contratação firmada, analisando se o produto ou serviço adquirido de fato atenderá às suas necessidades.

Insta pontuar que no aludido artigo, o legislador não previu especificamente a hipótese de arrependimento nas contratações firmadas pela internet, isto porque, no ano 1990, quando o Código entrou em vigor, as compras pela internet ainda não eram tão difundidas.

Todavia, em que pese essa omissão, as compras por meio da internet encontram-se inseridas tacitamente neste dispositivo, isto por que o Código ao se valer da expressão "especialmente" evidenciou que seu rol é meramente exemplificativo, e, por conta disso, dá margem para inserção de outras modalidades de contratação nesse mesmo contexto.

A temática já está pacificada pela doutrina conforme se observa:

quando a lei foi elaborada, ainda não existia a atual evolução a respeito das vendas pela internet ou outros meios de comunicação semelhantes ou próximos,

\footnotetext{
${ }^{34}$ Cf. MARQUES, Claudia Lima. Contratos no Código de Defesa do Consumidor - O novo regime das relações contratuais. $7^{\mathrm{a}}$ ed. São Paulo: Revista dos Tribunais, 2014, p. 909.
} 
devendo o referido dispositivo ser estendido para tais hipóteses, conforme reconhece a melhor doutrina. Nessa linha, posicionam-se, por todos, Nelson Nery Jr. e Rosa Maria de Andrade Nery, afirmando que "O CDC enumerou, de maneira exemplificativa, as formas de contratação fora do estabelecimento comercial: por telefone e a domicílio. O caráter de numerus apertus desse elenco é dado pelo advérbio 'especialmente' constante da norma ${ }^{35}$.

À vista disso, não há dúvidas acerca da aplicabilidade desta norma aos contratos eletrônicos.

Seguindo a análise do art. 49, havendo o arrependimento por parte do consumidor e tendo pagado eventual quantia ao fornecedor, a qualquer título e dentro do prazo de reflexão terá ele, de imediato, seu dinheiro integralmente ressarcido e monetariamente atualizado pelos índices oficiais, segundo prevê o parágrafo único do artigo em comento.

É importante destacar que o referido direito não pode ser restringido pelo fornecedor. Havendo cláusula no contrato que colida com esse direito será declarada nula conforme o art. 51, II do CDC.

Superada esta questão, outro ponto merece destaque: trata-se das despesas relativas ao frete e à postagem, entre outros encargos. Extinta a relação contratual pelo arrependimento a quem caberá custeá-las?

Os autores do anteprojeto do CDC entendem que caberá ao fornecedor arcar com tais custas:

O Código garante o direito de arrependimento, de forma pura e simples, sem que do consumidor se exija a declinação dos motivos que o levaram a arrependerse do negócio. A denúncia vazia do contrato de consumo é direito do consumidor, que não pode ser apenado com o pagamento das despesas oriundas

35 TARTUCE, Flávio et al. Manual de direito do consumidor. 3. ed. São Paulo: Método, 2014, p. 208/209. 
daquele contrato resolvido, justamente porque sua atividade é lícita e jurídica ${ }^{36}$.

O Superior Tribunal de Justiça também aplica o mesmo entendimento:

ADMINISTRATIVO. CONSUMIDOR. DIREITO DE ARREPENDIMENTO. ART. 49 DO CDC. RESPONSABILIDADE PELO VALOR DO SERVIÇO POSTAL DECORRENTE DA DEVOLUÇÃO DO PRODUTO. CONDUTA ABUSIVA. LEGALIDADE DA MULTA APLICADA PELO PROCON.

2. O art. 49 do Código de Defesa do Consumidor dispõe que, quando o contrato de consumo for concluído fora do estabelecimento comercial, o consumidor tem o direito de desistir do negócio em 7 dias ("período de reflexão"), sem qualquer motivação. Trata-se do direito de arrependimento, que assegura o consumidor a realização de uma compra consciente, equilibrando as relações de consumo.

3. Exercido o direito de arrependimento, o parágrafo único do art. 49 do CDC especifica que o consumidor terá de volta, imediatamente e monetariamente atualizados, todos os valores eventualmente pagos, a qualquer título, durante o prazo de reflexão, entendendo-se incluídos nestes valores todas as despesas com o serviço postal para a devolução do produto, quantia esta que não pode ser repassada ao consumidor.

4. Eventuais prejuízos enfrentados pelo fornecedor neste tipo de contratação são inerentes à modalidade de venda agressiva fora do estabelecimento comercial (internet, telefone, domicílio). Aceitar o contrário é criar limitação ao direito de arrependimento legalmente não previsto, além de desestimular tal tipo

${ }^{36}$ GRINOVER, Ada Pellegrini. Código Brasileiro de Defesa do Consumidor comentado pelos autores do anteprojeto. 9. ed. Rio de Janeiro: Forense Universitária, 2007, p. 563. 
de comércio tão comum nos dias atuais. 5. Recurso especial provido ${ }^{37}$.

O fundamento para que o fornecedor arque com estes custos se dá pela aplicação da teoria do risco: para ela, toda pessoa que exerce uma atividade no mercado está sujeita a arcar com os ônus desta, ou seja, os riscos ${ }^{38}$, e neste caso o risco é o consumidor exercer seu direito de arrependimento.

Portanto, depreende-se que se o direito de arrependimento do consumidor for exercido dentro prazo legal surtirá o efeito juridicamente denominado ex tunc, significa que os efeitos da desistência do contrato retroagirão ao início do negócio, isto é, como se nunca tivesse ocorrido a contratação.

Embora as normas do CDC tenham sido revolucionárias para a época de sua elaboração, percebeu-se que com o aperfeiçoamento das relações de consumo houve a necessidade de melhor abordar a temática do comércio eletrônico em especial no que toca o direito de arrependimento do consumidor. Por conta desse, entre outros motivos foi proposto o Projeto de Lei $n^{\circ}$ 281/2012 do Senado.

Esse projeto de lei tem como objetivo aperfeiçoar as disposições gerais do Capítulo I do Título I e ainda dispor sobre o comércio eletrônico.

No que interessa a este trabalho, o referido projeto traz algumas melhorias ao exercício do direito de arrependimento, entre elas define o que seja a contratação à distância, equipara a contratação à distância àquela firmada no estabelecimento, quando o consumidor não teve a prévia oportunidade de conhecer o produto ou serviço, por não se encontrar em exposição ou pela impossibilidade ou dificuldade de acesso a seu conteúdo e especifica como se dará a devolução de valores eventualmente pagos pelo consumidor.

\footnotetext{
${ }^{37}$ BRASIL. Superior Tribunal de Justiça. Recurso Especial no 1340604 / RJ - Brasília. Relator: Ministro Mauro Campbell Marques. Pesquisa de jurisprudência, Acórdãos, 09. Setembro. 2016. Disponível em: <https://ww2.stj.jus.br/processo/revista/documento/mediado/?componente $=$ ITA\&sequencial $=1255126 \&$ num_registro $=201201416908 \&$ data $=20130822 \&$ formato=PDF $>$. Acesso em: 09. Setembro. 2016. 38 Cf. DORNELES, Pablo Friedrich. A responsabilidade Civil Objetiva Prevista no CDC. Disponível em: <http://www.dalagnol.com.br/site.php?acao=ler\&menu=artigo\&codArtigo=3>. Acesso em: 20. Setembro. 2016
} 
Por meio da observação destas propostas de alterações, é perceptível que o legislador tem buscado ampliar e facilitar o exercício dos direitos previstos no $\mathrm{CDC}$, dentre eles o direito de arrependimento.

Frente ao exposto, não há dúvidas de que o direito de arrependimento do consumidor é uma das maiores ferramentas de proteções aos consumidores nos contratos de consumo eletrônicos, pois dá oportunidade aos consumidores de desistirem de uma contratação mal formulada ou até mesmo desnecessária, sendo, portanto, um dos direitos mais invocados nas relações de consumo eletrônicas.

\section{CONSIDERAÇÕES FINAIS}

Pelo exposto ao longo desse trabalho, foi possível identificar que com a expansão dos meios de comunicação, em especial a internet, as relações comerciais foram profundamente afetadas, pois a partir dela o comércio eletrônico se difundiu de forma inimaginável levando ao surgimento das relações de consumo eletrônicas.

Tais relações basicamente têm a mesma estrutura que as relações de consumo tradicionais, pois além de terem por base os mesmos princípios, apresentam requisitos idênticos para formação da relação jurídica como a necessidade de capacidade dos contratantes, a obrigação de licitude, a possibilidade jurídica do objeto do contrato, seja ele determinado ou determinável e por fim, o dever de estar de acordo com a lei.

A razão para o crescimento astronômico dessas relações de consumo ocorreu devido às mudanças de hábitos da sociedade que foram promovidas em razão da globalização.

O comércio eletrônico promoveu uma inovação na forma de contratar, pois por meio dele, não há a necessidade de um encontro físico entre os contratantes: basta que fornecedor e consumidor manifestem sua vontade por meio da internet. Essa novidade trouxe facilidade e comodidade aos contraentes para formalizarem o contrato.

Em que pese os benefícios e facilidades advindos por esta modalidade de contratação, certas circunstâncias abriram margem para que os fornecedores se valessem de sua posição econômica e jurídica superior a dos consumidores para lhes impor os termos e condições dos contratos. Tal conjuntura acentuou ainda mais o desequilíbrio existente entre eles. 
Para reduzir este poder autoritário dos fornecedores, foi aplicado a tais contratos o $\mathrm{CDC}$, que tem como principal objetivo promover justo equilíbrio nas relações de consumo, amparando os consumidores das práticas abusivas dos fornecedores.

Apesar desta proteção, identificou-se que, ao longo dos anos, o CDC não era suficiente para coibir as práticas abusivas dos fornecedores e oferecer aos consumidores proteção e segurança jurídica, pois, na época de sua promulgação, o comércio eletrônico não era uma prática comum e difundida na sociedade, além disso, sequer se imaginava a comercialização de produtos e serviços por meio da internet.

Foi então que, apenas recentemente, o legislador brasileiro redigiu normas mais específicas para defender os interesses desses indivíduos.

A primeira delas foi o Marco Civil da Internet (Lei $\mathrm{n}^{\circ}$ 12.965/14) que aborda a questão da clareza de informações e ainda trata da segurança jurídica acerca do que é disponibilizado na internet, aplicando-se tais regulamentações às relações de consumo eletrônicas.

A segunda foi o Decreto $n^{\circ} 7.962 / 13$, voltado especificamente para as relações de consumo eletrônicas, reforça as normas previstas no CDC e inova regulando especificamente sobre o comércio eletrônico.

Frente ao exposto, depreende-se que devido à emergência do comércio eletrônico, surgiram no mundo jurídico as relações de consumo eletrônicas. Em razão delas, foram criados mecanismos com o propósito de tutelar os consumidores dos riscos que, possivelmente, poderiam ser expostos, e ainda foram criados dispositivos que objetivam atenuar a desigualdade existente entre os consumidores e os fornecedores.

Um dos principais instrumentos de proteção desses consumidores é a possibilidade de exercício do direito de arrependimento (art. 49 do CDC), pois, por meio dele, os consumidores podem rescindir o contrato caso não se sintam seguros em relação ao produto ou serviço adquirido, ou até mesmo em razão da conduta dos fornecedores.

Extrai-se ainda que a aplicação destes institutos jurídicos às relações de consumo foi e continua sendo de grande valia para o aprimoramento dos contratos de consumo eletrônicos, pois a partir destes institutos tais contratos passaram a ser mais bem redigidos respeitando dispositivos do CDC e demais normas compatíveis com o tema.

Embora os contratos de consumo eletrônicos venham abordando aspectos do CDC e de demais normas jurídicas em seu conteúdo, é certo que ainda não foi atingido o ápice da proteção dos consumidores, pois por 
conta do rápido desenvolvimento do comércio eletrônico, a cada dia são levantadas novas questões que precisam ser solucionadas pelos legisladores.

Desse modo, o tema deve ser analisado com maior atenção pelos legisladores, visto que não basta a elaboração de normas que assegurem a proteção dos consumidores, de fato devem ser implementadas medidas que garantam a eficácia dos dispositivos protetivos como uma fiscalização mais rígida e eficiente.

Portanto, frente ao exposto, conclui-se que, cada vez mais, a temática da defesa do consumidor vem criando raízes na comunidade, pois a sociedade tem reconhecido a importância de se promover e respeitar os direitos dos consumidores, porém são necessárias melhorias não só no ordenamento jurídico, mas também na prática, para que estes direitos sejam de fato respeitados.

\section{REFERÊNCIAS BIBLIOGRÁFICAS}

BRASIL. Constituição da República Federativa do Brasil de 1988. Disponível em: http://www.planalto.gov.br/ccivil_03/constituicao/constituica ocompilado.htm. Acesso em: 21. Setembro. 2016.

Norma 004/95 (Uso de meios da rede pública de telecomunicações para acesso à internet). Disponível em: <http://www.anatel.gov.br/hotsites/Direito_Telecomunicacoes/Text oIntegral/ANE/prt/minicom_19950531_148.pdf>. Acesso em 22. Setembro.2016.

. Superior Tribunal de Justiça. Recurso Especial $n^{0}$ 1.195.642-RJ (2010/0094391-6). Recorrente: Empresa Brasileira de Telecomunicações S/A Embratel. Recorrida: Juleca 2003 Veículos LTDA. Relatora: Ministra Nancy Andrighi. Brasília, 13 de novembro de 2012. Disponível em: <https://ww2.stj.jus.br/processo/revista/inteiroteor/?num_registro= 201000943916\&dt_publicacao=21/11/2012>. Acesso em: 01 . Agosto. 2016.

. Superior Tribunal de Justiça. Recurso Especial no 1340604 / RJ Brasília. Relator: Ministro Mauro Campbell Marques. Pesquisa de jurisprudência, Acórdãos, 09. Setembro. 2016. Disponível em: 
<https://ww2.stj.jus.br/processo/revista/documento/mediado/?comp onente $=$ ITA\&sequencial $=1255126 \&$ num_registro $=201201416908$ $\&$ data $=20130822 \&$ formato=PDF $>$. Acesso em: 09. Setembro. 2016. . Superior Tribunal de Justiça. Recurso Ordinário no 27512 BA (2008/0157919-0). Recorrente: Banco Safra S/A. Recorrido: Plascalp Produtos Cirúrgicos LTDA. Relatora: Ministra Nancy Andrighi. Brasília, 20 de agosto de 2009. Disponível em <http://stj.jusbrasil.com.br/jurisprudencia/6031597/recursoordinariem-mandado-de-seguranca-rms-27512-ba-2008-01579190>. Acesso em: 07. Julho. 2015.

BENJAMIN, Antonio Herman V.; MARQUES, Cláudia Lima; BESSA, Leonardo Roscoe. Manual de Direito do Consumidor. $2^{\mathrm{a}}$ edição revista, atualizada e ampliada. São Paulo: Revista dos Tribunais, 2009.

BOECHAT, Marcos. O conceito de destinatário final para fins de aplicação do CDC. Disponível em <http://www.esinf.com.br/textode-apoio-detalhes/?id=5>. Acesso em: 20. Setembro. 2016.

BOLZAN, Fabrício. Direito do consumidor esquematizado. 2. ed. São Paulo: Saraiva, 2014.

CARVALHO, Kildare Gonçalves. Direito constitucional. 15. ed. rev., atual. e ampl. Belo Horizonte: Del Rey, 2009.

DORNELES, Pablo Friedrich. A responsabilidade Civil Objetiva Prevista no CDC. Disponível em: $<$ http://www.dalagnol.com.br/site.php?acao=ler\&menu=artigo\&co dArtigo=3>. Acesso em: 20. Setembro. 2016

GRINOVER, Ada Pellegrini. Código Brasileiro de Defesa do Consumidor comentado pelos autores do anteprojeto. 9. ed. Rio de Janeiro: Forense Universitária, 2007.

LENZA, Pedro. (Org.). Direito Civil 1 Esquematizado. $2^{a}$ ed. São Paulo: Saraiva, 2012.

LIMA, Maria Renata Barros de. A vulnerabilidade do consumidor no ecommerce. Disponível em: <https://jus.com.br/artigos/24601/avulnerabilidade-do-consumidor-no-e-commerce>. Acesso em: 20. Setembro. 2016.

MACHADO, Antônio Cláudio da Costa. Código Civil Interpretado artigo por artigo, parágrafo por parágrafo. $7^{\mathrm{a}} \mathrm{ed}$. Barueri: Manole, 2014. 
MARQUES, Claudia Lima. Caso Teka vs. Aiglon: em defesa da teoria finalista de interpretação do art. $2^{\circ}$ do CDC. Revista dos Tribunais. Vol. 36, 2000.

, Cláudia Lima. Confiança no comércio eletrônico e a proteção do consumidor. São Paulo: Revista dos Tribunais, 2004.

, Claudia Lima. Contratos no Código de Defesa do Consumidor O novo regime das relações contratuais $-7^{\mathrm{a}}$ ed. São Paulo: Revista dos Tribunais, 2014.

MOREIRA, M. E. S. COMÉRCIO ELETRÔNICO: a aplicação do direito do consumidor aos contratos de comércio eletrônico. 2010. 74 f. Trabalho de Conclusão de Curso - Centro Universitário de Brasília, Brasília. 2010.

NERY JR., Nelson. Código brasileiro de defesa do consumidor: comentado pelos autores do anteprojeto. p. 10. ed. Rio de Janeiro: Forense, 2011. v. I.

NUNES, Luis Antônio Rizzatto. Curso de direito do consumidor.7. ed. São Paulo: Saraiva, 2012.

O marco civil da internet entra em vigor. Disponível em: $<$ http://culturadigital.br/marcocivil/>. Acesso em: 01. Junho. 2015.

SILVA, Hugo Alves da. Destinatário final. Disponível em: <http://hugosilva.jusbrasil.com.br/artigos/221239377/destinatariofinal>. Acesso em: 25. Julho. 2016.

SOUZA, Maria Carolina Rosa de. Cláusulas contratuais abusivas nos contratos de consumo. Disponível em: <http://www.ambitojuridico.com.br/site/index.php?n_link=revista_artigos_leitura\&arti go_id=11277>. Acesso em: 04. Junho. 2016.

TARTUCE, Flávio et al. Manual de direito do consumidor. 3. ed. São Paulo: Método, 2014. 
